\title{
Agronegócio Sul-Americano: Uma análise do Comércio de Produtos Agropecuários entre Mercosul e União Europeia
}

\author{
Agronegocios sudamericanos: Un análisis de la comercialización de productos agrícolas entre el \\ Mercosur y la Unión Europea \\ South American Agribusiness: An analysis of the commercialization of agricultural products between \\ Mercosur and the European Union
}

Recebido: 30/04/2021 | Revisado: 06/05/2021 | Aceito: 19/06/2021 | Publicado: 01/07/2021

José Cândido da Silva Nóbrega

ORCID: https://orcid.org/0000-0002-0976-3763

Universidade Federal de Campina Grande, Brasil E-mail: jcandidosn@uol.com.br

Francisco das Chagas Bezerra Neto

ORCID: https://orcid.org/0000-0001-6232-4383

Universidade Federal de Campina Grande, Brasil

E-mail: chagasneto237@gmail.com

Rubenia de Oliveira Costa

ORCID: https://orcid.org/0000-0003-2559-2885

Universidade Federal de Campina Grande, Brasil

E-mail: rubeniaadm@gmail.com

Patrício Borges Maracajá

ORCID: https://orcid.org/0000-0003-4812-0389 Universidade Federal de Campina Grande, Brasil

E-mail: patriciomaracaja@gmail.com

Agílio Tomaz Marques

ORCID: https://orcid.org/0000-0001-8364-5063

Universidade Federal de Campina Grande, Brasil

E-mail: agiliotomaz@hotmail.com

\begin{abstract}
Resumo
Este trabalho visa analisar o comércio de produtos agropecuários entre Mercosul e União Europeia. Através do estudo bibliográfico foi possível verificar as relações comerciais internacionais até a elaboração do acordo entre Mercosul e União Européia. O objetivo geral do estudo foi analisar a evolução do comércio de produtos agropecuários entre Mercosul e União Europeia entre 2009 a 2019 e analisar o acordo comercial entre os dois blocos econômicos. A metodologia adotada foi a Revisão Bibliográfica a partir dos principais autores da área, seguida de um exemplo ilustrativo a partir da literatura. A pesquisa possibilitou algumas considerações e reflexões a respeito do tema como: a partir do acordo de livre comércio, o Mercosul tem chance de expandir seu agronegócio num patamar de importância global, porém alguns problemas de infraestrutura, devem ser superados, para agregar agilidade ao processo logístico de distribuição dos produtos; ao avaliar a integração comercial entre o Mercosul e a União Européia para produtos agropecuários, é possível concluir que a união europeia é o principal comprador dos insumos agropecuários do Mercosul e que esse tratado de livre comércio irá expandir esse mercado de forma diferenciada, tornando os países membros do Mercosul, os maiores produtores agropecuários do planeta.
\end{abstract}

Palavras-chave: Acordo comercial; Agronegócio; Negócios internacionais.

\begin{abstract}
This work aims to analyze the trade in agricultural products between Mercosur and the European Union. Through the bibliographic study it was possible to verify the international commercial relations until the elaboration of the agreement between Mercosur and the European Union. The general objective of the study was to analyze the evolution of trade in agricultural products between Mercosur and the European Union between 2009 and 2019 and to analyze the trade agreement between the two economic blocs. The adopted methodology was the Bibliographic Review from the main authors of the area, followed by an illustrative example from the literature. The research enabled some considerations and reflections on the theme, such as: from the free trade agreement, MERCOSUR has a chance to expand its agribusiness at a level of global importance, but some infrastructure problems must be overcome, to add agility to the process logistics of product distribution; when evaluating the commercial integration between Mercosur and the European Union for agricultural products, it is possible to conclude that the European Union is the main buyer of the agricultural inputs of Mercosur and that this free trade agreement will expand this market in a differentiated way, making the countries members of Mercosur, the largest agricultural producers on the planet.
\end{abstract}


Keywords: Trade agreement; Agribusiness; International business.

\section{Resumen}

Este trabajo tiene como objetivo analizar el comercio de productos agrícolas entre el Mercosur y la Unión Europea. A través del estudio bibliográfico se pudo verificar las relaciones comerciales internacionales hasta la elaboración del acuerdo entre Mercosur y la Unión Europea. El objetivo general del estudio fue analizar la evolución del comercio de productos agrícolas entre el Mercosur y la Unión Europea entre 2009 y 2019 y analizar el acuerdo comercial entre los dos bloques económicos. La metodología adoptada fue la Revisión Bibliográfica de los principales autores del área, seguida de un ejemplo ilustrativo de la literatura. La investigación permitió algunas consideraciones y reflexiones sobre el tema, tales como: a partir del tratado de libre comercio, el MERCOSUR tiene la posibilidad de expandir su agroindustria a un nivel de importancia global, pero algunos problemas de infraestructura deben ser superados, para agregar agilidad a la logística del proceso. de distribución de productos; Al evaluar la integración comercial entre Mercosur y la Unión Europea de productos agrícolas, es posible concluir que la Unión Europea es el principal comprador de los insumos agrícolas del Mercosur y que este tratado de libre comercio ampliará este mercado de manera diferenciada, convirtiendo a los países en miembros de Mercosur, los mayores productores agrícolas del planeta.

Palabras clave: Acuerdo comercial; Agroindustria; Negocios internacionales.

\section{Introdução}

Desde a década de 1990, observou-se, na América Latina, após fim dos regimes militares neste continente, ter havido uma continuação de regimes neoliberais e um processo de reforma e descentralização dos poderes no Estado e maior autonomia privada, principalmente na economia (Souza Neto, 2009).

Foram implementados mecanismos de cooperação transnacional, viabilizados por meio da intensificação da assinatura de tratados, convenções e protocolos, fundamentados na reciprocidade e auxílio mútuo. Tratados e acordos foram assinados de forma exponencial. O fenômeno da globalização, a expansão do comércio internacional e dos fluxos de capitais, impulsionado pelos avanços na tecnologia da informação e telecomunicações, apresenta grandes desafios para os países (Souza Neto, 2009).

O processo de integração económica na UE parte dos princípios estabelecidos no Acordo Geral de Tarifas Aduaneiras e Comércio GATT. De união aduaneira e mercado comum, transformou-se na Comunidade Econômica Européia, englobando as relações sociais, de direitos humanos e culturais em relação de igualdade com as relações econômicas.

A União Européia (UE) pode ser compreendido como um processo de integração econômica mais avançado e complexo do mundo, na atualidade, contando com a instituição de uma política macroeconômica coordenada e com o estabelecimento de uma moeda única (o euro) que provocou modificações significativas no contexto jurídico. Foram implementados mecanismos de cooperação transnacional, viabilizados por meio da intensificação da assinatura de tratados, convenções e protocolos, fundamentados na reciprocidade e auxílio mútuo. Tratados e acordos foram assinados de forma exponencial. O fenômeno da globalização, a expansão do comércio internacional e dos fluxos de capitais, impulsionado pelos avanços na tecnologia da informação e telecomunicações, apresenta grandes desafios para os países (Souza Neto, 2009).

É objetivo geral desse estudo: analisar a evolução do comércio de produtos agropecuários entre Mercado Comum do Sul (Mercosul) e UE entre 2009 a 2019 e analisar o acordo comercial entre os dois blocos econômicos. São objetivos específicos: Fazer uma análise da evolução do agronegócio no Brasil no período de 2009 a 2019; analisar o Acordo (Tratado) entre Mercosul e UE e as mudanças propostas no cenário do comércio internacional; avaliar a integração comercial entre o Mercosul e a União Europeia para produtos agropecuários; descrever a importância do agronegócio para o Brasil; refletir sobre o agronegócio sul- americano nas negociações com a União Europeia.

Visando o atingimento do objetivo proposto, esse trabalho foi dividido em alguns temas pesquisados a partir dos principais autores da área. Esses grandes temas foram: O Agronegócio no Brasil; Mercosul; A Compatibilização das Ordens Jurídicas dos Estados na Formação da Integração Regional; Relações Comerciais entre União Européia e Mercosul; Acordo de Livre Comércio entre Mercosul e União Européia. 


\section{Metodologia}

O estudo abordado "objetiva gerar conhecimentos novos úteis para o avanço da ciência sem aplicação prática prevista. Envolve verdades e interesses universais." (Prodanov, 2013 p. 51).

Irá tratar de um objetivo de pesquisa descritiva, que irá abordar o tema em sua amplitude e têm como objetivo primordial a descrição das características de determinada população ou fenômeno ou, então, o estabelecimento de relações entre variáveis (Gil, 2002).

De acordo com os procedimentos técnicos o estudo será classificado como estudo bibliográfico pois é feito a partir de materiais existentes sobre o assunto como por exemplo: livros, revistas, publicações em periódicos e artigos científicos, jornais, boletins, monografias, dissertações, teses, material cartográfico e internet. O objetivo é colocar o pesquisador em contato direto com vasto material, sobre o assunto da pesquisa (Prodanov, 2013).

Esse estudo foi desenvolvido em duas etapas. Inicialmente foi realizada uma revisão de literatura com a aplicação de uma pesquisa bibliográfica e posteriormente apresentado um estudo ilustrativo tendo como base fontes bibliográficas, três pontos foram analisados:

- O Mercosul e o comércio exterior de produtos agropecuários

- Integração agroalimentar internacional do Mercosul: exportação e importação

- Mercosul e União europeia

Para a elaboração da pesquisa bibliográfica foram selecionadas as principais bases de dados, o número de artigos encontrados e selecionados os principais autores a serem pesquisados. Os dados encontrados foram interpretados pelo método de análise qualitativa.

\section{Desenvolvimento}

Os setores de alimentos e agricultura estão enfrentando mudanças significativas. Alguns dos fatores mais importantes do agronegócio são os mesmos fatores que afetam outros setores, indústrias e economias em todo o mundo e estão criando novas oportunidades em mercados desenvolvidos e emergentes, com enorme potencial de crescimento para todo o setor (Heredia et al., 2010).

Os setores de alimentos e agricultura estão enfrentando mudanças significativas. Alguns dos fatores mais importantes do agronegócio são os mesmos fatores que afetam outros setores, indústrias e economias em todo o mundo e estão criando novas oportunidades em mercados desenvolvidos e emergentes, com enorme potencial de crescimento para todo o setor (Heredia et al., 2010).

Em 2011, a população mundial atingiu 7 bilhões de pessoas e se considerarmos que a Organização Mundial de Saúde recomenda 3 refeições por dia, precisamos de 21 bilhões de refeições todos os dias.

Em 2050, com uma população de 9,3 bilhões, o mundo precisará de quase 50\% mais comida. De 2010 a 2050, os agricultores precisarão produzir uma quantidade semelhante a tudo o que foi produzido desde o início da agricultura, em 10.000 a.C. Além disso, até 2030, 60\% da população mundial estará vivendo em áreas urbana (Santos, 2016).

A importante contribuição do Brasil para o agronegócio global é inquestionável. É o maior produtor e exportador mundial de café, açúcar e suco de laranja. É altamente classificado na produção e exportação de soja, milho, etanol, carne de porco, carne bovina e carne de frango.

Segundo o Ministério da Agricultura (2011) as projeções referentes ao café mostram que a produção deve se elevar a uma taxa média anual de 4,0\% no período 2019/2020, mas as estimativas feitas pelo DCAF - Departamento de Café do Mapa indicam que esse crescimento pode atingir uma taxa de até 9,0\% até 2013/2014 O consumo está estimado para crescer a cerca de 4,5\% ao ano nos próximos 10 anos. 
Figura 1: Produção, consumo e exportação de café.

\begin{tabular}{|c|c|c|c|}
\hline Ano & $\begin{array}{c}\text { Produção } \\
\text { (milhões/sc) }\end{array}$ & $\begin{array}{c}\text { Consumo } \\
\text { (milhões/sc) }\end{array}$ & $\begin{array}{c}\text { Exportação } \\
\text { (milhões/sc) }\end{array}$ \\
\hline $2010 / 11$ & 54 & 19,5 & 33,7 \\
\hline $2011 / 12$ & 50 & 20,4 & 34,5 \\
\hline $2012 / 13$ & 58,9 & 21,3 & 35,4 \\
\hline $2013 / 14$ & 54,5 & 22,3 & 36,3 \\
\hline $2014 / 15$ & 64,2 & 23,3 & 37,2 \\
\hline $2015 / 16$ & 59,4 & 24,3 & 39,1 \\
\hline $2016 / 17$ & 69,9 & 25,4 & 40,1 \\
\hline $2017 / 18$ & 64,8 & 26,5 & 41,1 \\
\hline $2018 / 19$ & 76,2 & 27,7 & 42,1 \\
\hline $2019 / 20$ & 70,6 & 29 & \\
\hline
\end{tabular}

Fonte: DCAF - Departamento de Café do Ministério da Agricultura, Pecuária e Abastecimento (2020).

No entanto, segundo a Embrapa (2020) atualmente há no Brasil uma elevação no número de desempregados e uma diminuição da renda dos trabalhadores. Num cenário pessimista, a pandemia do COVID-19 deixará 12,6 milhões de pessoas desempregadas no país, elevando a taxa atual de 11,6\% para 23,8\%. Como a carne bovina é elástica à renda, era de se esperar uma redução do consumo interno. Se o consumidor não tem renda, ele passa a selecionar o que consome e aumentar a demanda por proteína de menor valor agregado, como carne de frango e ovos. Além disso, o isolamento social leva ao fechamento de restaurantes, bares e hotéis, grandes compradores e importantes canais de distribuição de carne bovina, e o consumo passa a depender mais substancialmente do cliente doméstico, que busca preço, praticidade e mix de opções, atributos estes encontrados na carne de frango.

Uma redução substancial do consumo de carne bovina irá impor ajustes necessários nas escalas de abate das indústrias frigoríficas, visto que o consumo doméstico representa cerca de $80 \%$ do mercado total de carne bovina. A cada tonelada de carne bovina que deixa de ser consumida, diminui-se o abate de bovinos em números de cabeças, mantendo-se as exportações constantes. Nesse sentido, o mercado externo pode ser um fator determinante no desempenho do setor em 2020.

A China e os EUA, também têm grandes extensões de terra disponíveis, mas devem enfrentar problemas de água e temperatura de congelamento, respectivamente.

Os EUA também têm terras e boa tecnologia disponíveis para aumentar a produção agrícola em todo o mundo. Entre os fatores sociais e tecnológicos estão a disponibilidade de mão-de-obra humana, o conhecimento técnico acumulado ao longo de muitos anos de produção agrícola e pecuária e a busca contínua de inovação por instituições públicas e privadas de pesquisa e desenvolvimento (Heredia et al, 2010).

Os ambientes sociais, econômicos e políticos do Brasil, refletem a robustez de suas instituições nacionais, que operam à distância e supervisionam as regras políticas, legais e de mercado.

Atualmente, o país desfruta de legislação sólida, compromisso com a democracia, direitos humanos e desenvolvimento, essenciais para agricultores e agronegócios, pois garantem a propriedade da propriedade privada e clareza de regras. 
Portanto, quando as condições climáticas e os mercados são favoráveis, o retorno do investimento é garantido. Em termos de relações internacionais, o Brasil faz fronteira com dez países da América do Sul, e o bom relacionamento com todos eles floresceu como resultado de fortes esforços diplomáticos.

O mesmo pode ser observado no cenário global: o Brasil mantém boas relações com os principais países de todos os continentes e possui uma abordagem proativa nas principais questões da agenda internacional, como desenvolvimento sustentável, segurança internacional, cooperação, economia e comércio.

Como exemplo, o Brasil está fortemente representado no Fórum Econômico Mundial, e os muitos acordos de cooperação agrícola assinados com países africanos, são amplamente reconhecidos, por agências internacionais, como exemplares.

No plano econômico, o Brasil é atualmente a sétima maior economia do mundo com base no PIB. O país experimenta os benefícios do crescimento da renda e melhor distribuição de renda entre sua população; além disso, a classe média está crescendo, juntamente com a demanda por produtos mais industrializados e serviços de qualidade (Heredia et al, 2010).

A produção total do complexo oleaginoso e de grãos para a safra 2018/19 é estimada em aproximadamente 250,9 milhões de toneladas, com 65,4 milhões de hectares cultivados e produtividade de $3.833 \mathrm{~kg} / \mathrm{ha}$ - uma alta histórica e um aumento de 3,7\% em relação há último ano. A soja é a principal commodity agrícola do complexo de grãos e teve um aumento de 4,6\% no volume colhido - o Brasil será para esta temporada o maior produtor e exportador de soja. A colheita de milho também apresentou ótimos resultados, e o Brasil se tornou o maior exportador de milho, com 102 milhões de toneladas (CONAB, 2020).

Contudo a Conab (2020), diz que as estimativas para soja grão indicam uma produção brasileira de 86,5 milhões de toneladas em 2020/2021. Essa projeção é maior em cerca de 17,8 milhões de toneladas em relação ao que o Brasil deve produzir na safra de 2010/2011. A taxa de crescimento anual prevista para a produção é de 2,3\% no período da projeção, 2010/11 a 2020/2021. O consumo doméstico de soja em grão deverá atingir 45,6 milhões de toneladas no final da projeção, representando $52,7 \%$ da produção. Projeta-se um crescimento no consumo a uma taxa anual de 1,9\%. Como se sabe, a soja é um componente essencial na fabricação de rações animais e adquire importância crescente na alimentação humana.

Uma comparação internacional, mostra o Brasil emergindo como um ator líder em termos de terras disponíveis, com mais de 100 milhões de hectares disponíveis para crescimento, sem uma única árvore derrubada (Santos, 2016). Os EUA também têm terras e boa tecnologia disponíveis para aumentar a produção agrícola em todo o mundo. Entre os fatores sociais e tecnológicos estão a disponibilidade de mão-de-obra humana, o conhecimento técnico acumulado ao longo de muitos anos de produção agrícola e pecuária e a busca contínua de inovação por instituições públicas e privadas de pesquisa e desenvolvimento (Heredia et al., 2010).

\section{Mercosul}

O Mercosul foi oficialmente fundado por assinatura do Tratado de Assunção em 26 de março de 1991. No curso dessa assinatura, o caminho estava livre para a discussão e estabelecimento dos seguintes aspectos e objetivos: a livre circulação de bens, serviços e pessoas entre os Estados membros; a coordenação de políticas macroeconômicas e setoriais entre os Estados Partes do Mercosul da respectiva política industrial, monetária e fiscal; a política comercial; política agrícola, política de comunicação, política de serviço e transporte e a harmonização da confirmação dos Estados membros e da legislação nas áreas em questão a alcançar um reforço do processo de integração global (Trindade, 2007).

Após o desenvolvimento do Mercosul no final dos anos 90, os Estados membros do Bloco introduziram o "relançamento do Mercosul", em 2000. Os Estados membros descreveram este "relançamento do Mercosul" como "a nova 
etapa da integração regional". Esta iniciativa tem e defende o objetivo de reforçar a união aduaneira dentro e fora dentro dos países participantes (Comissão Europeia, 2010).

O Mercosul é um processo de integração que começa a partir do Tratado de Assunção, assinado pela Argentina, República Federativa do Brasil, República do Paraguai e República do Uruguai, através do seu próprio instrumento firmado um bloco de cooperação internacional. Do ponto de vista constitucional, de cada Estado membro do Mercosul, diferentes realidades são observadas, e cada país enfrenta diversos e singulares problemas na compatibilização destas normas derivadas do Mercosul no seu âmbito interno (Trindade, 2007).

De acordo com o Tratado de Assunção, em 1991, o objetivo do Mercosul é: "compromisso dos Estados Partes de harmonizar suas legislações nas áreas pertinentes, a fim de fortalecer o processo de integração" (artigo $1^{\circ}$ ). Encontra-se uma lei que estabelece um padrão de liderança dos Estados Partes: Argentina, Brasil, Paraguai e Uruguai, a obrigação de harmonizar as suas legislações em certos setores e áreas legais que são considerados relevantes para a consolidação do mercado comum (Trindade, 2007).

\section{Relações Comerciais entre UE e Mercosul}

A UE pode ser considerada o primeiro parceiro comercial do Mercosul, representando aproximadamente $19,8 \%$ do comércio total do Mercosul com o resto do mundo e um valor de 109895 milhões de euros em 2013.

A internalização de normas emanadas dos órgãos do Mercosul pelos Estados-Membros coloca problemas críticos tanto para determinar a natureza jurídica do âmbito do direito Mercosul, tanto como para definir o grau de formação de requisitos para conseguir a incorporação das normas dentro do sistema jurídico dos stakeholders.

Sem dúvida, a questão da constituição e posterior aplicação dos regulamentos do Mercosul deve ser analisada a partir dos pressupostos estabelecidos no Tratado de Assunção (doravante TÁ), o Protocolo de Ouro Preto (doravante POP) e as regras derivadas, além das autorizações constitucionais estipulados por cada Estado-parte (Trindade, 2007).

O tratado de livre comércio entre Mercosul e União Europeia, é um acordo de livre comércio que foi assinado no dia 28 de junho de 2019, dependentemente do processo de ratificação. Esse acordo foi firmado entre os membros do Mercosul e UE, com o objetivo de estabelecer as práticas de livre comércio entre eles.

Vieira et al. (2019) ainda ressalta que os resultados venham a se concretizar a médio e longo prazos, espera-se um maior dinamismo de complementaridade entre as economias dos dois blocos, seja no comércio de produtos e serviços, seja em investimento.

As principais relações externas do Mercosul, foram desenvolvidas com a União Europeia, embora o objetivo acordado em 1995, para a criação de uma associação estratégica e de livre comércio, ainda não tenha sido alcançado.

As relações entre os dois blocos são baseadas no "Acordo-Quadro de Cooperação", assinado em 1995, que fornecem diretrizes e os objetivos para preparar a associação bi-regional entre eles (Baptista, 1996). Segundo Palmieri (2019) no caso de frutas que o Brasil é basicamente exportador (como manga, melão, melancia, mamão, citros e banana), o acordo deve ser bastante favorável, ainda que alguns não tenham desgravação imediata da tarifa - limões e limas, melancias e melões, por exemplo, devem ter as tarifas zeradas em sete anos.

Segundo a CitrusBR, as tarifas para entrada de suco de laranja brasileiro no bloco europeu variam entre $12 \%$ e $15 \%$, a depender das especificações do produto. Portanto, a redução gradual das tarifas sobre o suco de laranja nacional na Europa pode compensar, em parte, a possível perda da competitividade da commodity em relação a outros tipos de sucos e bebidas no bloco. vinhos, alguns terão isenção de tarifas em até oito anos, o que pode permitir que vinhos europeus cheguem ao consumidor brasileiros a valores mais atrativos - o que pode diminuir a competitividade do produto nacional. 
Além disso, pode elevar o Market share dos vinhos europeus frente a outros importados - segundo a Secex, em 2018, $25 \%$ dos vinhos importados pelo Brasil vieram do bloco. a batata pré-frita congelada: Ainda que o Brasil esteja elevando a sua produção interna, a maior parte da batata pré-frita congelada consumida no País é importada, sendo que, em 2018, 26\% foram originárias da UE, segundo a Secex. Atualmente, a batata pré-frita importada tem tarifa de 14\%, e, para este produto, além de elevar o Market share europeu, o acordo pode limitar ainda mais a competitividade da batata processada brasileira - visto que a congelada importada já chega ao Brasil a preços bastante competitivos.

Quanto ao tomate, as processadoras brasileiras importam parte de sua necessidade de polpa de tomates (não apenas por não haver produção interna suficiente, mas também por questões estratégicas e de qualidade) - em 2018, 19\% das importações vieram do bloco europeu. Este, portanto, seria mais um caso de possibilidade de aumento do Market share da polpa europeia.

\section{Considerações Finais}

Historicamente, a necessidade urgente, de aumentar as exportações agrícolas, leva ao aumento da produtividade através da capitalização do agronegócio e da aplicação das novas tecnologias (mecanização, sementes selecionadas, irrigação, fertilizantes químicos, pesticidas). Também traz uma reorganização das áreas agrícolas e uma expansão das culturas comerciais, destinadas a satisfazer a crescente demanda global de alimentos para consumo da população mundial.

Com o acordo de livre comércio, o Mercosul tem uma chance ímpar de expandir seu agronegócio para um patamar de importância global, porém inicialmente alguns problemas históricos, como infraestrutura, devem ser superados, para assim agregar agilidade ao processo logístico de distribuição dos produtos a serem exportados. Problema que se destaca principalmente no Brasil, principal exportador do bloco, apesar da existência de grandes espaços agrícolas e do crescimento da produção e exportação de soja, derivados cítricos e cana-de-açúcar.

Desssa forma, conclui-se ao analisar o comércio de produtos agropecuários do Mercosul, que este segmento, é ainda o carro chefe da economia sul - americana e que não existe a curto e médio prazo dados que prevejam uma mudança dessa importância do setor para os países membros do mercosul.

Nesse diapasão, levando em consideração essa necessidade de assegurar, de forma eficaz, o crescimento econômico inerente ao mercado, acreditamos que investigações como esta devem ser prosseguidas. Sendo assim, como sugestão para continuidade de discussões nesse sentido, analisar, à luz do Mercado Internacional, de que modo os investimentos relacionados aos produtos agropecuários podem ser implementa com o fito de melhorar o desempenho destes no âmbito internacional.

\section{Referências}

Baptista, L. O. (1996). O Mercosul após o Protocolo de Ouro Preto. Estudos avançados, 10.

Basso, M. (2000). Harmonização dos direitos dos países do MERCOSUL. Revista de Direito do MERCOSUL, n. 6.

Comissão Europeia. (2010). COM (2010) 348 final. Livro Verde da Comissão sobre as opções estratégicas para avançar no sentido de um direito europeu dos contratos para os consumidores e as empresas. Acesso em 02 dezembro 2020, em http://eurlex.europa.eu/LexUriServ/LexUriServ.do?uri.

CONABE, Companhia Nacional de Abastecimento. (2020). Observatorio agrícola: Acompanhamento da Safra Brasileira.

EMBRAPA, Empresa Brasileira de Pesquisa Agropécuaria. (2020). Os impactos da COVID-19 para a cadeia produtiva da carne bovina brasileira

Gil, A. C. (2002). Como elaborar projetos de pesquisa. (4a ed.), Atlas.

Heredia, B., Palmeira, M., \& Leite, S. P. (2010). Sociedade e Economia do "Agronegócio" no Brasil. Revista brasileira Ci. Soc., 25, 74. http://www.scielo.br/scielo.php?script=sci_arttext\&pid=S0102.

Ministério Da Agricultura, Pecuária E Abastecimento. (2011). Brasil projeções do agronegócio 2010/2011 a 2020/2021.

Prodanov, C. C., \& Freitas, E. C. de. (2013). Metodologia do trabalho científico: Métodos e Técnicas da Pesquisa e do Trabalho Acadêmico. (2a ed.), Universidade FEEVALE.

Santos, L. P. dos et al. (2016). Brazilian agribusiness in international trade. Rev. de Ciências Agrárias, 39, 54-69 http://www.scielo.mec.pt/scielo.php 
Research, Society and Development, v. 10, n. 7, e52510715629, 2021

(CC BY 4.0) | ISSN 2525-3409 | DOI: http://dx.doi.org/10.33448/rsd-v10i7.15629

?script=sci_arttext\&pid=S0871-

Souza Neto, C. P. de (2009). Constitucionalismo democrático e governo das razões: estudos de direito constitucional contemporâneo. Lumen Juris.

Trindade, O. A. D.Cançado.(2007). O MERCOSUL no direito brasileiro: incorporação de normas e segurança jurídica. Del Rey.

Vieira, S. et al. (2019). Acordo Mercosul-UE deve baratear produtos, mas forçar eficiência e produtividade. 